\title{
Kearifan Lokal Bertajuk Religi dalam Mite Gunung Tidar: Kajian Antropologi Sastra
}

\author{
Fikha Nada Naililhaq \\ Universitas Gadjah Mada \\ fikhanada11@gmail.com
}

\begin{abstract}
How to cite (in APA Style): Naililhaq, F.N. (2019). Kearifan Lokal Bertajuk Religi dalam Mite Gunung Tidar: Kajian Antropologi Sastra. Jurnal Pendidikan Babasa dan Sastra, 20(1), 61-70. DOI: https://doi.org/10.17509/bs_jpbsp.v20i1.25972
\end{abstract}

Article History: Received (20 February 2020); Revised ( 25 March 2020); Accepted (1 April 2020)

Journal homepage: http://ejournal.upi.edu./index.php/BS_JPBSP

\begin{abstract}
Abstrak: Mite Gunung Tidar merupakan salah satu sastra lisan yang berkembang di sekitar masyarakat Magelang, Jawa Tengah. Penelitian ini bertujuan untuk mendiskripsikan tentang religiusitas dalam mite Gunung Tidar dengan tinjauan antropologi sastra. Sumber data penelitian ini berasal dari mite atau mitos yang berkembang di masyarakat sekitar. Metode pengumpulan data yang dilakukan dengan dua tahapan yakni library research yang dilanjutkan dengan field research. Metode deskriptif analitik digunakan untuk menganalisis data-data yang telah diperoleh. Hasil penelitian ini menunjukan adanya korelasi antara religi dengan kebudayaan masyarakat setempat, khususnya kebudayaan Jawa. Korelasi keduanya tercermin pada tradisi Syababiyah, Ruqyah, Korelasi antara Kyai Semar dalam Mite Gunung Tidar dengan Semar dalam Pewayangan, dan Simbol atau Situs Kebudayaan yang Berada di Gunung Tidar.
\end{abstract}

Kata kunci : kearifan lokal; religi; mite Gunung Tidar; antropologi sastra

\section{Local Wisdom Titled Religious in the Myth of Tidar Mountain: Study of Literary Anthropology}

\begin{abstract}
The Myth of Tidar Mountain is one of oral literature that flourishing around people of Magelang, Middle Java. This research aimes to describe religiosity in The Myth of Tidar Mountain with review of literary anthropology. The data source of this research came from myth that flourishing around the people. The data collecting method was done by two phase which is library research and continued with field research. Descriptive analytic method was used to analyzed the data that have been collected. The result of this research shows the correlation between religion and local people culture, especially Javanese culture. The correlation of both is reflected in Syababiyah tradition, Ruqyah, Correlation between Kyai Semar in Myth of Tidar Mountain with Semar in puppet show, and symbol or culture sites in Tidar Mountain.
\end{abstract}

Keywords : local wisdom; religion; Myth of Tidar Mountain; literary anthropology 


\section{PENDAHULUAN}

Sastra lisan disebut sebagai salah satu budaya yang terdapat dalam suatu masyarakat. Sastra lisan juga disebut sebagai bagian dari karya sastra yang memiliki kaitan erat dengan kehidupan masyarakat. Bentuk sastra lisan mempunyai keunikan tersendiri disetiap daerah, hampir setiap daerah mempunyai sastra lisan yang berbeda-beda. Sastra lisan mempunyai banyak fungsi yang sangat menarik untuk dikaji para ahli sastra dan psikolog untuk melaksanakan pembangunan bangsa (Danandjaja, 2002, p.19).

Dalam sastra lisan terdapat kearifan lokal yang masih bertahan dan dipertahankan oleh masyarakat melalui sebuah cerita atau mite. Oleh karena itu, kearifan yang terdapat dalam sastra lisan senantiasa dijaga oleh masyarakat agar tidak hilang ditelan zaman. Walaupun zaman senantiasa berubah, kearifan lokal mampu berperan untuk menata kehidupan masyarakat. Salah satu aspek yang menonjol pada kearifan lokal yaitu aspek religi. Religiusitas inilah yang dapat mengatur tatanan kehidupan masyarakat setempat.

Pada penelitian ini akan dikaji aspek religiusitas yang menjadi kearifan lokal pada mite di Gunung Tidar. Dalam mite Gunung Tidar terdapat cerita yang dipercaya oleh masyarakat setempat. Cerita atau mite tersebut menarik untuk dikaji, untuk mengetahui kearifan lokal yang terdapat di dalamnya. Gunung Tidar bukanlah gunung dalam arti yang sesungguhnya. Gunung Tidar sebenarnya adalah sebuah bukit yang tingginya 503 meter dari pemukaan laut. Letak Gunung Tidar berada di tengah Kota Magelang, tepatnya di desa Magersari, Kota Magelang, Jawa Tengah. Gunung Tidar dijadikan sebuah tempat wisata yang banyak dikunjungi oleh wisatawan, baik wisatawan asli Magelang maupun luar Magelang. Di atas Gunung Tidar terdapat berbagai macam situs budaya yang menjadi daya tarik tersendiri oleh wisatawan. Wisatawan yang berkunjung kebanyakan melakukan wisata rohani atau wisata religi. Hal ini sesuai dengan situs budaya yang terdapat di Gunung Tidar, seperti makam Syekh
Subakir, makam Kyai Sepanjang (pakuhning tanah Jawi), makam Kyai Semar (Eyang Ismoyo), tugu puseran bumi tanah jawa, dan tugu tiang bendera Akademi Militer.

Di dalam Gunung Tidar terdapat mite yang dipercaya oleh masyarakat setempat. Mite tersebut diceritakan secara turun temurun dari nenek moyang kepada masyarakat, sehingga terdapat keterkaitan antara masyarakat setempat dengan mite yang berkembang di Gunung Tidar. Alasan peneliti mengkaji mite Gunung Tidar karena masih sedikit penelitian yang mengkaji mite tersebut. Padahal mite Gunung Tidar mempunyai potensi untuk dikaji lebih dalam agar mengetahui karakteristik kearifan lokal yang ada di dalamnya, khususnya aspek religiusitas. Aspek religiusitas yang terdapat dalam mite Gunung Tidar lah yang menjadi fokus permasalahan yang akan dikaji dalam penelitian ini.

Dalam membongkar aspek religi yang terdapat pada mite Gunung Tidar, digunakan kajian antropologi sastra sebagai teori untuk mengkaji mite tersebut. Antropologi sastra dijadikan sebagai kajian teori karena beberapa alasan, pertama aspek religi masuk ke dalam tujuh unsur kebudayaan. Kedua, antropologi sastra sebuah kajian yang berhubungan dengan kubudayaan serta masyarakat. Ketiga, adanya perspektif antropologi sastra dalam sastra lisan mite yang terdapat di Gunung Tidar. Hal itulah yang mendasari digunakannya antropologi sastra dalam penelitian ini.

Antropologi sastra merupakan studi mengenai karya sastra dengan relevansi manusia. Antropologi menekankan pada aspek budaya masyarakat sebagai kelompok variabel yang berinteraksi. Sementara sastra diyakini sebagai refleksi kehidupan masyarakat pendukungnya. Hal ini dapat diidentifikasikan bahwa antropologi sastra merupakan disiplin ilmu yang interdisepliner, serta termasuk studi baru dalam mengkaji karya sastra. Isu mengenai antropologi sastra pertama kali muncul pada tahun 1977 melalui kongres 'Foklore and Literary Anthropology' yang berlangsung di Calcutta (Ratna, 2015,p.352). Lahirnya ilmu antropologi dipicu oleh tiga sebab utama, 
(a) baik sastra maupun antropologi menganggap bahasa sebagai objek penting, (b) kedua disiplin ilmu yang mempermasalahkan relevansi manusia dan budaya, dan (c) kedua disiplin ilmu juga membahas tentang tradisi lisan. Menurut Bruner (1993: 1) Makna sebuah fenomena penelitian budaya maupun sastra bersifat secara radikal akan bersifat plural, terbuka, dan kadang-kadang bersifat politis.

Menurut Keesing (dalam Endraswara, 2013, p.23) bahasa mempunyai kaitan sebagai alat komunikasi, dari sisi antropologi sastra dapat berimbas ke bidang antropologi sastra. Oleh karenanya, bahasa diwujudkan dalam sastra oleh sekelompok orang yang membungkus makna simbolis dengan bahasa kias. Perilaku budaya masyarakat dituturkan sejara imajinatif oleh informan secara lisan. Tuturan secara lisan memiliki banyak tafsiran jika diteliti. Antropologi sastra sangat cocok untuk mengkaji simbol-simbol budaya, karya-karya baik lisan maupun tertulis yang memuat kearifan lokal atau warna lokal (Endraswara, 2013, p.24).

Menurut Endraswara, terdapat keterkaitan antara antropologi sastra dengan etnografi. Etnografi berisi muatan seluk beluk manusia dan hal-hal yang bersifat humanistik. Etnografi juga erat kaitannya dengan sebuah tradisi, sementara antropologi sastra merupakan kajian sastra yang menekankan pada budaya masa lalu. Warisan budaya ini, dapat tergambar dalam karya-karya sastra klasik dan modern (Ridington \& Ridington, 1993, p. 49). Hal ini menyebabkan perlunya menyeleksi karya sastra ketika akan menggunkan antropologi sastra atas keberagaman dan lokalitasnya

Mite Gunung Tidar disebut sebagai salah satu satu karya yang bergenre lisan. Sastra lisan yang terdapat di Indonesia banyak jenis dan macamnya. Banyak pula sastra lisan yang hilang ditelan zaman karena tidak ada yang mengembangkan kembali kelisanan tersebut, namun tidak menutup kemungkinan bahwa terdapat di beberapa daerah yang masih melestarikan sastra lisan hingga saat ini. Sastra lisan yang berkembang dimasyarakat biasanya memiliki beberapa versi cerita. Hal ini disebabkan karena sifatnya yang dikembangkan turun-temurun secara lisan sehingga menyebabkan beberapa perbedaan cerita yang ada. Menurut Teeuw (1994, p.3) perkembangan sastra lisan tentang puisi rakyat dilakukan oleh Parry and Lord. Parry and Lord mengungkapkan bahwa teknik penciptaan epos rakyat diturunkan dari guru kepada murid. Parry and Lord berkesimpulan bahwa epos rakyat tidak dihafalkan secara turun-menurun, melainkan diciptakan kembali secara spontan. Si penyanyi atau pelantun puisi lisan memiliki persediaan formula yang disebut stock-in-trade. Dengan adanya variasi merupakan ciri dari puisi lama.

Menurut Teeuw (dalam Baihaqi 2017), di Indonesia memungkinkan sastra lisan berubah terus menerus, walaupun beberapa ragam dasar bertahan sama. Sesuai yang diungkapkan Teeuw tersebut bahwa satra lisan dalam perkembangannya pasti terdapat perbedaan-pebedaan, namun hal itu tidak menjadi masalah. Meskipun teridentifikasi adanya perbedaan, dasar cerita atau fomula yang dilisankan tetap sama, hanya dikembangkan sedikit oleh para penutur sastra lisan.

Sastra lisan juga termasuk kearifan lokal yang berhubungan kebijaksanaan atau pengetahuan asli dari suatu masyarakat yang berasal dari nilai luhur tradisi budaya untuk mengatur tatanan kehidupan masyarakat (Sibarani, 2018). Kearifan lokal dapat dilihat dari cerita rakyat atau mite yang beredar di kalangan masyarakat setempat. Kearifan lokal dapat dikatakan sebagai tradisi turuntemurun yang diwariskan oleh nenek moyang untuk mengatur kehidupan masyarakat disegala bidang. Bentuk kearifan lokal biasanya disesuaikan dengan kondisi masyarakat di mana kearifan lokal tersebut lahir.

Kearifan lokal terdiri dari kedamaian dan kesejahteraan. Kedamaian terdiri atas kesopanan, kejujuran, kesetiakawanan sosial, kerukunan, penyelesaian konflik, komitmen, pikiran positif, dan religi. Sementara kearifan lokal kesejahteraan meliputi, kerja keras, disiplin, pendidikan, 
kesehatan, gotong royong, pengelolaan gender, pelestarian dan kreativitas budaya, serta peduli lingkungan (Sibarani, 2018, p.134). Religi merupakan salah satu unsur penting dari kearifan lokal. Religi muncul karena adanya manusia yang percaya pada kekuatan gaib yang lebih tinggi darinya, penyebab manusia itu melakukan hal dengan cara-cara yang beragam untuk dapat berkomunikasi dengan kekuatan tersebut (Koentjaraningrat, 2015, p.294). Semua aktivitas manusia yang bersangkutan dengan religi didasarkan pada suatu getaran jiwa yang biasa disebut dengan emosi keagamaan. Emosi keagamaan ini lah yang membuat orang melakukan tindakantindakan yang bersifat religi. Dengan demikian, emosi keagamaan meupakan unsur penting religi bersama tiga unsur lainnya, yaitu (a) sistem keyakinan; (b) sistem upacara keagamaan; (c) umat yang menganut religi tersebut (Koentjaraningrat, 2015, p.295). Walaupun demikian, religi tidak hanya menyangkut masalah keagamaan, melainkan juga budaya, situs, maupun sejarah.

Penelitian lain yang telah membahas tradisi dan mitos yaitu penelitian Rahayu (2015) yang bertujuan untuk menggambarkan secara tekstual dan mitos dalam bahasa Jawa untuk cerita pendek Nyanyian Kesetiaan oleh Miftah Fadhli and Friends serta untuk menggambarkan konstruksi tradisi dan mitos Jawa dalam cerita pendek. Metode untuk menganalisis data adalah deskriptif analitik. Penelitian ini menggunakan pusat pendekatan antropologi sastra dalam antropologi teks yang berfokus pada pemikiran, ide, budaya, tradisi dan mitos yang tercermin dalam karya sastra. Penelitian ini menunjukkan bahwa tradisi Jawa dalam cerita pendek, antara lain kunjungan bhakti ke tradisi tempat ziarah, pernikahan suku Jawa seperti, upacara seremonial (Slametan), tradisi vasting Jawa, dan membersihkan tradisi desa. Sementara mitos-mitosnya seperti energi diri, roh leluhur, sesajen, dan tabu untuk menikah antara desa Cipaku dan Onje. Sedangkan, konstruksi tradisi dalam cerpen seperti, budaya Hidhuis dan Budhis ada dalam ziarah, agama Jawa ada dalam dua tradisi, dan konstruksi pra Hindhuis dan Budhis.

Penelitian serupa dengan ini juga dilakukan oleh Setyorini pada tahun 2017 dengan judul "Kajian Arkeptipal dan Nilai Kearifan Lokal Legenda di Kota Purworejo serta Relevansinya sebagai Bahan Ajar Mata Kuliah Kajian Prosa". Penelitian ini bertujuan untuk mendeskripsikan kajian arkeptipal legenda di Purworejo, mendeskripsikan nilai kearifan lokal legenda di Kota Purworejo, dan relevansi kajian arkeptipal dan nilai kearifan lokal di Kota Purworejo sebagai bahan ajar dalam mata kuliah Kajian Prosa Fiksi.Metode penelitian yang digunakan adalah deskriptif kualitatif. Hasil penelitian ini menjelaskan tentang (1) kajian arkeptipal dalam legenda di Purworejo yang membahas legenda Dewi, Candi Ngasinan, Banyuurip, dan Brengkelan; (2) kearifan lokal yang ada dalam legenda berupa upacara adat, bahasa, dan mata pencaharian; (3) penelitian ini relevan sebagai bahan ajar dalam mata kuliah pengkajian sastra baik materi psikologi sastra maupun antropologi sastra.

Ada pula penelitian dari Ihsan (2018) yang bertujuan untuk mendeskripsikan aspek bahasa, aspek religi, sosial, serta aspek politik dalam novel Ranggalawe: Mendung di Langit Majapahit karya Gesta Bayuadhy. Penelitian ini menggunakan metode kualitatif hermeneutika. Hasil yang diperoleh dalam penelitian ini ialah (1) bahasa yang digunakan ialah bahasa Jawa senapa dan bahasa Indonesia, (2) aspek Religi masyarakat jawa ialah penganut kepercayaan Hindu Budha, (3) aspek sosial para tokoh dalam novel ini tidak semuanya memiliki sosial yang baik dan tinggi seperti raja Wilwatikta Dyah Wijaya dan Sahasika, ada pula yang tokoh yang memiliki sosial rendah seperti Halayudha, yang terlalu mementingkan kepentingan pribadi sehingga menimbulkan perang saudara.

Dari ketiga penelitian yang telah ada sebelumnya, terdapat perbedaan dan persamaan antar penelitian tersebut dengan penelitian yang akan diteliti. Perbedaan terletak pada fokus penelitian, objek formal, maupun objek material. Selain itu, juga 
terdapat persamaan antara penelitian orang yang telah dipaparkan dengan penelitian yang akan di lakukan. Dari keempat penelitian tidak ada persamaan melalui objek material, namun terdapat kesamaan dalam objek formalnya. Hal ini dikarenakan peneliti tidak menemukan artikel penelitian yang meneliti tentang mite Gunung Tidar.

\section{METODE}

Penelitian ini merupakan penelitian kualitatif, dengan dua tahapan metode pengumpulan data yakni Library Research dan Field Research. Library Research dilakukan dengan cara obserasi. Observasi merupakan kegiatan pengamatan data yang dilakukan oleh peneliti. Pengamatan dilakukan melalui artikel, foto, dan video. Kemudian dilanjutkan dengan Field Research yang merupakan pengumpulkan data dengan cara penelitian lapangan secara langsung. Field Research dilakukan dengan cara wawancara bersama narasumber juru kunci Gunung Tidar untuk mengetahui mite atau cerita lisan yang terdapat di objek wisata tersebut. Wawancara dilakukan setelah peneliti melakukan observasi.

Metode analisis data adalah seperangkat cara atau teknik penelitian yang disebut sebagai perpanjangan dari pikiran manusia karena fungsinya bukan untuk mengumpulkan data, melainkan untuk menarik hubungan antardata (Faruk, 2012, p.25). Dalam penelitian ini analisis data yang digunakan yaitu deskriptif analisis. Hal ini dilakukan dengan cara memaparkan faktafakta yang terdapat dalam data, kemudian dianalisis serta dideskripsikan dengan memberikan pemahaman dan penjelasan.

\section{HASIL DAN PEMBAHASAN}

Pada bagian pembahasan, peneliti akan menguraikan aspek religiusitas yang terdapat dalam mite Gunung Tidar. Aspek religiusitas yang tedapat dalam mite Gunung Tidar tidak semata-mata berhubungan dengan agama saja, namun ada pula hubungannya dengan unsur kebudayaan, seperti cerita pewayangan serta situs kebudayaan yang terdapat di Gunung Tidar.
Berikut ini akan diuraikan aspek religiusitas yang terdapat dalam mite Gunung Tidar.

\section{Syababiyah dan Ruqyah}

Mite yang terdapat di Gunung Tidar sangat menonjol dalam unsur religi. Unsur religi berkaitan dengan unsur budaya masyarakat setempat, karena unsur budaya ini dianut secara turun temurun sehingga menjadi kebudayaan di lingkungan masyarakat. Unsur religiusitas dalam mite Gunung Tidar bercorak Islam. Terdapat dua amalan dalam mite tersebut yang sampai saat ini masih dilaksankan oleh masyarakat setempat, yaitu syababiyah dan ruqyah.

Syababiyah atau ruqyah dalam pandangan agama islam merupakan pembacaan doa-doa dengan tujuan atau maksud tetentu. Syababiyah merupakan nama lain dari ruqyah yang sering digunakan oleh masyarakat ketika meminta doa kepada pemuka agama, baik ustad maupun kyai. Istilah syababiyah masih banyak digunakan pada masyarakat sekitar Gunung Tidar. Pada mite yang terdapat di Gunung Tidar, syababiyah atau ruqyah juga sudah dilakukan oleh Syekh Subakir dengan tujuan tertentu. Berikut ini data yang membahas tentang syababiyah.

Pertemuan Syekh Subakir dengan Eyang Ismoyo memuat suatu dialog dan pejanjian-pejanjian. Salah satu pejanjiannya dengan cara Syekh Subakir diajak pergi ke padepokan agung Eyang Ismoyo yaitu Alas Purwo. Eyang Ismoyo mengatakan bahwa "jika anda bisa nyabdo atau merubah air sumur menjadi wangi, aku dan para dedemit tidak akan tinggal di pulau Jawa, namun akan tinggal di pesisir selatan atau pantai selatan. Kemudian Syekh Subakir menyabdo air semur tersebut. Air di satu sumur bisa menjadi wangi, sedangkan di sumur satunya tidak bisa menjadi wangi (Sumarlan/ 21 September 2019).

Dari data yang telah diuraikan di atas, diketahui bahwa adanya kesepakatan antara 
Eyang Ismoyo dengan Syekh Subakir yang dilakukan di alas Purwo yaitu tempat padepokan agung yang dimiliki oleh Eyang Ismoyo. Di sana terdapat dua sumur yang baunya busuk. Syekh Subakir diminta untuk nyabdo sumur atau mengharumkan kedua sumur tersebut, agar ia bisa menetap di Pulau Jawa khususnya sekitar Gunung Tidar yang berada di Magelang. Nyobdo sama halnya dengan syababiyah ataupun ruqyah. Hal pertama yang dilakukan Syeikh Subakir adalah menerima tantangan tersebut, kemudian ia membacakan doa-doa yang diambilnya dari Al-Qur'an agar merubah air tersebut menjadi harum. Pembacaan doadoa dengan ayat Al-Qur'an, assunah, serta dzikir menyebut nama Allah dalam islam disebut ruqyah atau syababiyah. Tujuannya adalah untuk menetralkan suatu hal, baik itu barang, tempat bahkan manusia agar terlepas dari ganggungan dedemit, jin, setan, dan lainnya.

Terdapat pebedaan antara ruqyah atau sababiyah yang dilakukan Syekh Subakir dengan ruqyah yang dikenal oleh masyarakat sekarang. Ruqyah atau Sababiyah yang dilakukan Syekh Subakir lebih menonjolkan doa-doa untuk bendabenda mati atau tidak bernyawa, seperti barang, tempat, ataupun lainnya. Namun tidak menutup kemungkinan bahwa ruqyah dapat diaplikasikan dalam beberapa hal lainnya. Sementara ruqyah yang sekarang dikenal oleh banyak masyarakat luas yaitu cara menyembuhkan, atau menangkal penyakit-penyakit tertentu yang berhubungan dengan santet, jampi-jampi, ataupun gangguan dari setan (kerasukan).

Dalam merubah bau air sumur, Syekh Subakir hanya mampu merubah satu sumur menjadi harum, sedangkan satunya tetap berbau busuk. Kedua sumur tersebut mempunyai arti dua kehidupan yang berbeda. Satu sumur yang berbau harum menandakan kehidupan manusia, sementara sumur yang berbau busuk menandakan kehidupan jin dan setan. Hal tersebut menandakan bahwa antara kehidupan manusia dan jin yang lebih tinggi derajat maupun kedudukan adalah manusia. Adanya dua kehidupan tersebut untuk menyejajarkan kehidupan di dunia serta untuk keseimbangan alam. Dimana ada harum pasti akan ada bau busuk, dan dimana ada orang baik pasti ada orang jahat. Maka dari itu, manusia harus berhati-hati dalam bertindak.

Selain nyabdo air sumur, ada juga ruqyah atau sababiyah yang dilakukan Syekh Subakir di Gunung Tidar. Hal ini sesuai dengan data yang dijelaskan oleh narasumber, data yang dimaksud sebagai berikut.

Setelah itu, Syekh Subakir kembali ke tanah pusaran lagi. Dengan bantuan tombak daya pusaka yang bernama Kyai Sepanjang, serta diridhoi oleh Tuhan maka Syekh Subakir melakukan sababiyah atau ruqyah di Gunung Tidar. Dengan tujuan agar gunung Tidar bisa tentrem. Kemudian para dedemit takluk, dan saat itulah baru manusia bisa hidup di tanah Jawa. Jadi sebelum ditumbali, disababiyah atau diruqyah oleh Syekh Subakir, manusia tidak mampu hidup ditanah Jawa karena ganasnya para demit pada saat itu. Dedemit pada masa itu ganas, namun ketika Syekh Subakir menggunakan doa-doa lafal Al-Quran untuk meruqyah, dedemit akan hangus dan sebagian akan menyingkir dari situ (Sumarlan/ 21 September 2019).

Sesuai dengan data yang dipaparkan di atas, setelah melakukan sabdo di alas Purwo dan berhasil merubah bau satu sumur, maka Syekh Subakir kembali ke Gunung Tidar Magelang untuk meruqyahnya. Syekh Subakir memilih Gunung Tidar sebagai alasan karena letaknya berada persis di tengah-tengah pulau Jawa sesuai dengan cerita mite tersebut yang masih diyakini masyarakat setempat hingga saat ini. Gunung Tidar dipercaya oleh masyarakat sebagai titik tengah pulau Jawa. Hal tersebut dapat dilogika karena letak Gunung Tidar yang istimewa yaitu di tengah Kota Magelang. Sangat jarang terdapat gunung atau bukit yang berada di tengah kota, alasan ini 
menjadi dasar kenapa Gunung Tidar disebut sebagai tengah atau titik nol Pulau Jawa.

Sama halnya dengan dilakukan Syekh Subakir pada dua sumur yang berbau busuk, ketika sampai di Gunung Tidar ia juga melakukan hal yang sama. Dikisahkan pada saat itu pulau Jawa masih belum stabil, layaknya perahu dilautan yang masih goyah dan bisa karam ketika ada gelombang. Dengan begitu ketika Syeikh Subakir datang, bertujuan untuk menentramkan bumi tanah Jawa dengan bantuan tombak pusaka yang diiringi dengan doa-doa.

Pulau Jawa masih berguncang seperti kapal dilautan dapat diartikan bahwa pada saat ini masyarakat pulau Jawa, khusunya daerah Magelang masih dalam kebimbangan dan keresahan. Belum ada panutan atau pedoman yang pas untuk dijadikan pegangan hidup tentang cara bernteraksi, baik interaksi sosial maupun interaksi dengan alam. Sehingga sewaktu-waktu mereka bisa hancur dan bercerai-berai ketika dihadapi oleh sebuah permasalahan. Dengan datangnya Syekh Subakir, masyarakat seperti mendapat guru yang menuntun mereka agar senantisa hidup sesuai dengan tuntutan agama, khususnya agama Islam. Setalah Gunung Tidar di sababiyah atau diruqyah dengan dibacakan doa-doa yang terdapat dalam Al-Qur'an oleh Syekh Subakir, maka manusia bisa datang untuk bertempat tinggal di sekitar Gunung Tidar. Artinya, manusia bisa hidup rukun, damai serta teloran antarsesama setelah datang agama Islam yang dibawa oleh Syekh Subakir. Mite tersebut sebagai simbol penyebaran Islam dilakukan oleh Syekh Subakir, seorang pemuka agama yang berasal dari Turki.

\section{Korelasi antara Kyai Semar dalam Mite Gunung Tidar dengan Semar dalam Pewayangan}

Mite di Gunung Tidar juga tidak lepas dari unsur kebudayaan yang sangat menonjol. Unsur kebudayaan yang ada tentunya budaya Jawa sesuai dengan letak mite Gunung Tidar. Dalam hal unsur budaya ini akan ada korelasi antara Eyang
Ismoyo dengan cerita pewayangan, khususnya cerita tentang Semar. Dalam mite yang terdapat di Gunung Tidar Eyang Ismoyo mempunyai julukan atau nama lain, yaitu Kyai Semar. Berikut data yang menjelaskan Eyang Ismoyo.

Eyang Ismoyojati adalah seorang pemomonge atau raja tanah Jawa yang diciptakan oleh Tuhan yang Maha Agung pada saat bumi tanah Jawa masih goyang. Penghuni tanah Jawa pada saat itu adalah para dedemit, jin, dan setan. Eyang Ismoyojati diciptakan oleh Tuhan Sang Pencipta untuk momong tanah jawa sampai 1100 tahun (Sumarlan/21 September 2019).

Sesuai data yang dipaparkan narasumber, bahwa sebelum ada manusia di Pulau Jawa Tuhan telah menciptakan Eyang Ismoyo untuk menjadi pengasuh atau raja di Jawa. Pada saat itu penghuni tanah Jawa hanyalah para dedemit, jin, dan setan yang sangat ganas. Dalam hal ini, Eyang Ismoyo menjadi raja para dedemit tersebut, namun wujud dari Eyang Ismoyo bukanlah dedemit, jin, maupun setan. Ada indikasi kepecayaan masyarakat sekitar Gunung Tidar yang menyatakan bahwa Kyai Semar merupakan Nabi utusan Tuhan yang bertugas untuk menjaga tanah Jawa dan seisinya termasuk jin, setan, dan iblis. Sama halnya dengan tokoh Semar dalam pewayangan yang dianggap sebagai raja pemimpin para ksatria Jawa. Semar digunakan sebagai simbol penutan, kejujuran, dan teladan bagi masyarakat. Hal ini ditunjukan melalui kepribadian dan perilaku tokoh Semar dalam pewayangan. Dalam pewayangan Semar dikatakan sebagai seorang dewa.

Pernyataan antara hubungan Eyang Ismoyo dengan tokoh Semar dalam pewayangan juga dituturkan oleh narasumber seperti pada data berikut.

Sunan Kalijaga yang menggunakan sifat, watak Eyang Ismoyo untuk dijadikan satu cerita yang namanya cerita pewayangan, yang digunakan sebagai gambaran, contoh untuk umat 
manusia. Dalam cerita tersebut yang dijadikan tanda contoh yaitu Kyai Semar. Semar itu adalah gambaran, tuladha, pewayangan atau bisa disebut sebagai gambaran pitutur luhur (Sumarlan/21 September 2019).

Berdasarkan data yang telah disebutkan di atas, bahwa Sunan Kalijaga mengadaptasi tokoh Eyang Ismoyo dalam cerita pewayangan yang diciptakannya untuk media dakwahnya. Hal ini membuktikan adanya sifat pemimpin yang arif, bijaksana, dan bisa menjadi panutan bagi masyarakat pada diri Eyang Ismoyo. Hal inilah yang diidentifikasi sebagai alasan Sunan Kalijaga mengadaptasi cerita Eyang Ismoyo dalam pewayangan. Dalam cerita pewayangan juga diceritakan bahwa nama lain dari Semar yaitu Ismoyo. Orang yang dapat dijadikan contoh bagi kehidupan masyarakat.

Masyarakat Jawa sering mengakronimkan suatu hal untuk disesuaikan dengan kondisi sosial pada masa itu. Seperti tokoh Semar yang diakronimkan sebagai Sira Eling Marang Allab lan Rasul, maksudnya adalah dari tokoh Semar tersebut menggambarkan bahwasanya sebagai umat beragama harus selalu ingat akan adanya Allah dan Rasulnya. Masyarakat diharusnya untuk senantiasa beribadah dan meminta petunjuk kepada Allah dalam menjalankan kehidupannya.

\section{Simbol atau Situs Kebudayaan yang Berada di Gunung Tidar}

Simbol merupakan suatu tanda tentang suatu hal. Simbol dalam hal ini berhubungan dengan nilai kearifan lokal yang terdapat dalam mite. Terdapat banyak simbol yang ada di dalam mite tersebut. Simbol-simbol yang terdapat dalam Gunung Tidar ada hubungannya dengan unsu religiusitas yang terdapat dalam mite atau cerita. Simbol atau situs tersebut seperti, bangunan makam, tugu pusaran tanah Jawa, paku tanah Jawa, dan tugu tiang bendera akmil.

Di atas Gunung Tidar terdapat tiga makam yang menjadi situs budaya serta banyak dikunjungi para peziarah dari berbagai kota. Ketiga makam tersebut yaitu makam Syekh Subakir, Kyai Sepanjang, dan Kyai Semar. Pada makam Syekh Subakair tidak ada yang istimewa dari segi bangunan dan perlakuannya. Hanya saja ketika peziarah ingin memasuki makam harus melepas alas kaki sebelum pintu gerbang makam. Hal ini menunjukan adanya sifat sopan santun masyarakat Jawa terhadap tokoh yang dihormati, agar tempat tersebut selalu bersih dan suci. Bangunan makam Syekh Subakir berbentuk bundar atau lingkaran. Bangunan tersebut mempunyai makna bahwa lingkaran itu seperti kehidupan manusia, yang mengikat dan membina seluruh masyarakat dalam sebuah kelompok. Ikatan yang digunakan yaitu agama berfungsi untuk membimbing masyarakat agar senantiasa rajin dan taat beribadah. Semakin tekun masyarakat taat beribadah, maka lingkaran akan semakain besar. Artinya kelompok umat agama akan semakain tersebar luas.

Selanjutnya, Makam Kyai Sepanjang, makam tersebut berbeda dengan kedua makam lainnya. Berikut ini data yang menyebutkan tentang makam Kyai Sepanjang.

Pakuning bumi tanah Jawa itu adalah Kyai Sepanjang. Kyai Sepanjang adalah makam tombak punya Syekh Subakir yang diridhoi oleh Tuhan untuk ditanam disertai dengan doadoa atau ruqyah sehingga bumi ini bisa menjadi tentram. Para dedemit pun takluk dan manusia dapat hidup ditanah Jawa. Setelah dirukyah oleh Syekh Subakir (Sumarlan/ 21 September 2019).

Kyai Sepanjang disebut sebagai pakubning tanah Jawi artinya Kyai Sepanjang menjadi pakunya tanah Jawa. Paku hanyalah sebuah simbol, sebenarnya Kyai Sepanjang berbentuk tombak pusaka yang digunakan oleh Syekh Subakir untuk meruqyah dan mengusir dedemit yang berada di tanah Jawa.

Situs selanjutnya yaitu tugu pusaraning Tanah Jawa. Tugu tersebut dikatakan sebagai pusaran atau titik tengah pulau Jawa, seperti penjelasan data berikut. 
Tugu sa sa sa sebagai tugu puseran bumi tanah Jawa (titik nol) yang ditengah tengah pulau Jawa (Sumarlan/ 21 September 2019).

Tugu sa sa sa atau tugu pusaran tanah Jawa dikatakan sebagai titik pusat atau titik tengah pulau Jawa. Tugu sa sa sa mempunyai akronim sapa salab seleh, sopo sholat slamet. Tugu ini menjadi sebuah nasihat kepada masyarakat untuk tidak melakukan kesalahan-kesalahan dalam hidupnya. Selain itu juga masyarakat diminta untuk rajin dan taat beribadah kepada Tuhan. Tugu pusaran tanah Jawa dapat dikatakan titik tengah pulau Jawa disebabkan tugu tersebut terletak di tengah tanah lapang yang luas di atas Gunung Tidar. Selain itu, tugu pusaran juga terletak ditengah-tengah diantara situs-situs yang terdapat di Gunung Tidar. Dua situs dibawah tugu pusaran yaitu makam Syekh Subakir dan Kyai Sepanjang, sedangkan yang berada di atas tugu pusaran yaitu tugu Akmil dan makam Kyai Semar. Hal ini lah yang diidentifikasi tugu sa sa sa sebagai tugu pusaran tanah Jawa.

Di atas tugu sa sa sa terdapat Tugu Akmil. Tugu Akmil ini berfungsi sebagai gambaran tentang adanya dukungan Gunung Tidar terhadap kebesaran Akademi Militer, hal ini sesuai yang dituturkan oleh narasumber sebagai berikut.

Tugu tiang bendera Akmil dibuat di Gunung Tidar untuk memberi contoh kebesaran Akademi militer karena adanya dukungan dari Gunung Tidar (Sumarlan/ 21 September 2019).

Tugu Akmil dibangun di Gunung Tidar untuk menandakan bahwa terdapat sebuah Akademi Militer yang berada di lembah Gunung Tidar. Tugu tersebut dijadikan sebuah simbol yang menandakan kebesaran dan kemegahan Akmil ditandai dengan tugu yang besar dan tinggi. Filosofi yang terdapat dalam Tugu Akmil bahwasanya Gunung Tidar mendukung pendidikan Akmil. Akmil pun demikian, ia tidak melupakan sejarah serta kebudayaan yang terdapat di Gunung Tidar. Para taruna
Akmil akan di ajak untuk mendaki Gunung Tidar supaya mengenal sejarah, tradisi, serta kebudayaan yang ada.

Makam Kyai Semar terletak di ujung puncang Gunung Tidar atau bisa disebut berada paling tinggi diantara situs-situs yang lainnya. Bangunan makam Kyai Semar berbeda dengan makam Syekh Subakir dan Kyai Sepanjang. Makam Syekh Subakir dan Kyai Sepanjang mempunyai bentuk bangunan yang terbuka, sedangkan makam Syai Semar bentuk bangunannya sangat tertutup. Diantara ketiga makam yang berada di Gunung Tidar, makam Kyai Semar adalah bentuk bangunan yang paling unik dan menarik.

Bangunan makam Kyai Semar berbentuk seperti tumpeng berwarna kuning yang dikelilingi oleh pager berbentuk kotak. Sehingga bentuk bangunan makam Kyai Semar yaitu kerucut, mengerucut ke atas. Bangunan ini berarti bahwa Kyai Semar merupakan simbol masyarakat yang berada di Pulau Jawa. Masyarakat mempunyai sifat, perilaku, dan keyakinan yang berbeda-beda. Dalam hal ini Kyai Semar mengingatkan bahwa walaupun masyarakat mempunyai banyak perbedaan namun nantinya mereka akan kembali kepada Tuhan. Meskipun masyarakat mempunyai cara yang berbeda-beda dalam beribadah, namun tujuan mereka tetap sama, yaitu untuk berserah diri kepada Tuhan. Selain itu, pintu masuk menuju makam sangat pendek sehingga setiap orang yang ingin memasuki makam harus menunduk agar kepala tidak membentur pintu. Hal ini mempunyai arti bahwa, setiap orang yang akan memasuki makam akan memberi penghormatan kepada Kyai Semar dengan cara menundukkan kepala. Selain itu, pintu ini juga menerminkan tentang sifat manusia harus rendah hati dan saling menghormati antarsesama masyarakat.

Pada makam Kyai Semar juga terdapat mitos yang dipercaya oleh masyarakat. Mitos tersebut hanya berlaku pada makam Kyai Semar saja, tidak berlaku di makam Syekh Subakir dan Kyai Sepanjang. Mitosnya bahwa jika ada yang berfoto di dalam makam Kyai Semar maka 
akan mendapatkan malapetaka. Mitos tersebut dapat dilogika bahwa makam merupakan suatu tempat yang sakral, sehingga tidak boleh difoto atau diabadikan secara langsung. Adanya mitos untuk membuat masyarakat percaya untuk tidak berfoto di dalam makam. Masyarakat juga akan lebih berahati-hati dalam bertindak mengabadikan gambar.

\section{SIMPULAN}

Mite Gunung Tidar sebagai sastra lisan perlu dijaga kelestariannya. Mite tersebut mengandung kearifan lokal yang secara turun temurun diperoleh dari nenek moyang. Kearifan lokal yang terdapat dalam mite Gunung Tidar yang paling menonjol adalah tentang religiusitas. Meskipun tidak menutup kemungkinan adanya kebudayaan serta simbol atau situs-situs berharga yang ada. Unsur kebudayaan yang tergembar yaitu hubungan antara Kyai Semar atau Eyang Ismoyo dengan tokoh Semar dalam pewayangan. Kedua tokoh tersebut mempunyai korekasi atau hubungan. Untuk situs-situs yang terdapat di Gunung Tidar antara lain, makam Syekh Subakir, Makam Kyai Sepanjang atau pakuhning tanah Jawi, Tugu sa sa sa atau pusaran tanah Jawa, tugu Akmil, dan makam Kyai Semar

\section{DAFTAR RUJUKAN}

Baihaqi, I. (2017). Karakteristik Tradisi Mitoni di Jawa Tengah sebagai Sebuah Sastra Lisan. Jurnal Arkhais, $8(2), \quad$ 136-156. Doi: https://doi.org/10.21009/ARKHAIS .082 .05

Bruner, J. S. (1993). The Culture of Education. Harvard University Press.

Danandjaja, J. (2002). Foklor Indonesia, Ilmu Gosip, Dongeng dan lain-lain. Jakarta: Pustaka Utama Grafiti.
Endraswara, S. (2013). Metodologi Penelitian Antropologi Sastra. Yogyakarta: Ombak.

Faruk. (2012). Metode Penelitian Sastra. Yogyakarta: Pustaka Pelajar.

Ihsan, B., \& Zuliyanti, S. (2018). Kajian Antropologi Sastra dalam Novel Ranggalawe: Mendung di Langit Majapahit Karya Gesta Bayuadhy. PENTAS: Pendidikan Bahasa dan Sastra Indonesia, 4(1), 33-40.

Koentjaraningrat. (2015). Pengantar Ilmu Antropologi. Jakarta: PT Rineka Cipta.

Rahayu, P. (2015). Tradisi dan Mitos Masyarakat Jawa dalam Kumpulan Cerpen Nyanyian Kesetiaan Karya Miftah Fadhli dkk (Kajian Antropologi Sastra). Doctoral dissertation, Universitas Muhammadiyah Purwokerto.

Ratna, N. K. (2015). Teori, Metode, dan Teknik Penelitian Sastra. Yogyakarta: Pustaka Pelajar.

Ridington, R. \& Jillian R. (1993). When You Sing It Now, Just Like New: First Nations Poetics, Voices and Representations. Linccoln: University of Nebraska Press.

Setyorini, N. (2017). Kajian Arkeptipal dan Nilai Kearifan Lokal Legenda di Kota Purworejo serta Relevansinya sebagai Bahan Ajar Mata Kuliah Kajian Prosa. Literasi: Jurnal Ilmiah Pendidikan Babasa, Sastra Indonesia dan Daerah, 7(2), 94-102. Doi: https://doi.org/10.17509/bs_jpbsp.v $17 \mathrm{i} 2.9659$.

Sibarani, R. (2018). Batak Toba society's local wisdom of mutual cooperation in Toba lake area: a linguistic anthropology study. International Journal of Human Rights in Healthcare.

Teeuw, A. (1994). Indonesia: Antara Kelisanan dan Keberaksaraan. Jakarta: Pustaka Jaya. 